\title{
Cytogenetic Analysis on the Yields of Chromosomal Aberrations Induced by the Scattered Doses of $y$-Radiation
}

Samit B. Kadam ${ }^{1 *}$, Soorambail K. Shyama ${ }^{1}$, Praveen Kumar MK ${ }^{1}$, Avelyno D'costa ${ }^{1}$ and Valentine G. Almeida

${ }^{1}$ Departments of Zoology, Goa University, Goa-403206, India

${ }^{2}$ Departments of Radiation Oncology, Goa University, Goa-403206, India

*Corresponding authors: Samit B. Kadam, Departments of Zoology, Goa University, Goa-403206, India, Tel: +91- 0832- 6519364; E-mail: samitk81@gmail.com

Received date: Aug 16, 2015, Accepted date: Nov 30, 2015, Publication date: Dec 04, 2015

Copyright: ( 2015 Kadam SB, et al. This is an open-access article distributed under the terms of the Creative Commons Attribution License; which permits unrestricted use; distribution; and reproduction in any medium; provided the original author and source are credited.

\begin{abstract}
The present study is undertaken to know the radiation dose-response of chromosomes in the non-target cells, viz. peripheral blood lymphocytes of cancer patients in a context of partial body irradiation. The genotoxic effect of $\mathrm{Y}-$ radiation was studied in Head and Neck Squamous Cell Carcinoma (HNSCC) patients exposed to various cumulative doses of ${ }^{60} \mathrm{Co}$ gamma rays during radiotherapy $(R T)$. These patients $\left(P_{1}\right.$ to $\left.P_{10}\right)$ were irradiated for a period of six weeks with a daily fraction of $2 \mathrm{~Gy}$, consecutively for 5 days in every week. The clastogenic effects of radiation in these patients were analysed on every weekend employing chromosomal aberration (CA) assay. Radiosensitivity of these patients were analysed by employing linear regression analysis of the CAs induced by irradiation. Genetic damage observed in all patients on a weekly basis were recorded and analysed at the individual level in comparison with their own pre-therapy baseline data, employing student's t-test. Dicentrics, centric rings and chromatid breaks were observed as the major kinds of CAs. The total CAs observed were analyzed using two way ANOVA, showed significant $(P<0.001)$ intra and inter-individual variations of the genotoxic effects. Further, a dose dependent increase of cytogenetic damage was observed in the non-target cells viz. lymphocytes. Further, cytogenetic studies in peripheral lymphocytes following gamma radiotherapy of tumors may help to understand the optimum/precise dose of radiation to be employed for RT, may also be useful to predict dosimetry and the possible secondary tumors in irradiated HNSCC patients.
\end{abstract}

Keywords: HNSCC patients; $\gamma$-radiation; Lymphocytes; CAs; Biodosimetry

\section{Introduction}

Head and neck squamous cell carcinoma (HNSCC) represents the seventh most common cancer globally, with approximately 47,000 new cases reported every year [1]. Cigarette smoking/tobacco consumption is a major cause of HNSCC [2-4]. Around $50 \%$ of the 10.9 million people diagnosed with cancer worldwide each year require RT, $60 \%$ of who are treated with curative intent. RT is the most important nonsurgical modality for the curative treatment of cancer. Ionizing radiation is a ubiquitous environmental physical agent whose DNA damaging effects are fairly well established. Although, the exposure of patients to radiation during radiotherapy is a beneficial use of radiation to improve the health of the individuals, ionizing radiation being a proven mutagen besides damaging killing tumour tissue may also induce genetic damage in the neighbouring/adjacent non-target cells. Genetic damage induced by radiation or other mutagens in nontarget cells is most frequently monitored in peripheral blood leukocytes [5]. A key challenge in RT is to maximize radiation doses to cancer cells while minimizing damage to the surrounding non-target healthy tissue. Recent literature in the field of clinical oncology and RT still does not explain sufficiently the question of damages to non-target cells and tissues after chemo-radiation treatment [6-8].

In order to obtain information concerning the extent of radiation exposure, its distribution and dose assessment, various biological methods have been developed. Human bio-monitoring can be performed using various genetic markers which detect early biological effects, including evaluation of DNA mutations, CAs, the induction of micronuclei and sister chromatid exchanges [9]. Among the various cytogenetic parameters employed, the most reliable biological indicators of ionizing radiation exposure are CAs in peripheral blood lymphocytes $[10,11]$.

The CA assay is often employed for monitoring the populations exposed to genotoxic agents because it allows the evaluation of the entire genome to identify mutagenic and carcinogenic agents [12]. Quantification of CAs in circulating lymphocytes is being used to estimate the dose received by individuals exposed to ionising radiation during RT and also the genetic damage prevailing in the whole body $[13,14]$. The number of peripheral lymphocytes exposed to irradiation during RT will vary in various HNSCC patients depending upon the exact target area and the quantum of radiation absorbed. Studies on HNSCC patients is of great significance as this part of human body covers a large number of blood vessels, lymph nodes and is a very sensitive region to irradiation.

Cytogenetic assessment of the lymphocytes of cancer patients undergoing localised fractionated therapeutic irradiation would evaluate the clastogenic effect induced by such treatment in the patient's circulating blood. The analysis of CAs in peripheral blood lymphocytes is often being used as a biomarker of health outcome, measuring genetic damage due to radiation that results from nonrepaired primary lesions. Hence, in order to know the quantum of genetic damage induced by various doses of gamma rays in the nontarget cells of cancer patients and their inter-patient variability, HNSCC patients receiving fractionated RT were selected as the subjects for the present study and further analysis was carried out. 


\section{Material and Methods}

\section{Study subjects}

Ten volunteer HNSCC patients aspiring for RT at Goa Medical College, Goa, India who were free of other major ailments and were not previously been treated with either chemotherapy or RT were selected as subjects for the present study after their written consent. Information related to them, including their smoking/tobacco consumption and medical history were collected by employing a specific questionnaire. Laboratory handlings of subjects and all other investigations were carried out in accordance with a high standard of ethics and guidelines of the Institutional Ethics Committee, Goa Medical College, Goa, India.

\section{Radiotherapy}

Tumour field sizes of each of these HNSCC patients were determined with $\mathrm{CT}$ scan and their target sites for irradiation were earmarked. All the patients $\left(\mathrm{P}_{1}-\mathrm{P}_{10}\right)$ underwent standardized externalbeam partial body irradiation with curative intent for localized tumour with a ${ }^{60} \mathrm{Co}$ source consisting of lateral fields of head and neck, with an average $1.25 \mathrm{MeV} \gamma$-ray beam to the target area. They received radiation for five week(s) at a $10 \mathrm{~Gy}$ dose per week, up to a cumulative tumor dose of $60 \mathrm{~Gy}$.

\section{Cytogenetic studies}

\section{Whole blood culture}

Intravenous blood samples were obtained from the subjects with HNSCC before starting the RT treatment $(0 \mathrm{~Gy})$ and later on (six times) at six consecutive weekly intervals of RT during the course of treatment $(10,20,30,40,50$ and 60 Gy). Five millilitres of blood was collected from each patient and evacuated into heparinized collection tubes. Culture was put up according to Scarfi et al. [15] and Siddique et al. [16]. In brief, $0.5 \mathrm{ml}$ of whole blood was added to $5 \mathrm{ml}$ of RPMI 1640 medium (Himedia-with L-glutamine and without sodium bicarbonate) containing $1 \mathrm{ml}$ of heat inactivated $10 \%$ fetal bovine serum (Himedia), $0.1 \mathrm{ml}$ of phytohemagglutinin (Himedia) and $0.2 \mathrm{ml}$ of antibiotics (Himedia- with $200 \mathrm{mM} \mathrm{L}$-glutamine, 1000 units $/ \mathrm{ml}$ penicillin and $10 \mathrm{mg} / \mathrm{ml}$ streptomycin). Culture was incubated at $37^{\circ} \mathrm{C}$ for 48 hour.

\section{Preparation of metaphase plate}

Cells in culture were treated with $0.1 \mathrm{ml}$ of $0.1 \%$ colchicine for 2 hours prior to harvesting at 48 hours of inoculation. Hypotonic acetic flame dry technique was performed at 48 hour of incubation involving steps such as hypotonic treatment $(0.075 \mathrm{M} \mathrm{KCl})$, fixation (methanolacetic acid 3:1), dropping 10-20 ul of cell suspension with a pasture pipette on chilled slides and heating. Metaphase plates were stained with $5 \%$ Giemsa stain.

\section{Chromosomal aberration analysis}

A total of 100 metaphase plates were observed per individual using trinocular research microscope (Olympus BX 53, Japan) and the CAs in each plate were analyzed and scored as per Savage [17].

\section{Statistical analysis}

Differences in CAs between control and treated samples, as well as between the smoker and non-smoker patients were analyzed employing students t-test to know the significance. Radiosensitivity of individuals for different doses of RT was analyzed by employing linear regression coefficient test [18]. A two-way ANOVA was carried out to evaluate the inter-individual (between the patients) variation of CAs and intra-individual variation between CAs at various doses of gamma radiation (0 Gy to $60 \mathrm{~Gy}$ ) and their respective pre-therapy (0 Gy) values. The null-hypothesis $\left(\mathrm{H}_{\mathrm{o}}\right)$ that "there are no inter and intra individual differences" was tested at 95\%, 99\%, 99.9\% confidence intervals.

\section{Result}

The quantitative CAs noted in the peripheral lymphocytes of the patients $\left(\mathrm{P}_{1}-\mathrm{P}_{10}\right)$ prior to RT and after various dose/weekly intervals of treatment are summarized in Table 1 and graphically displayed in Figures 1 and 2. The average CAs values of total patients (smokers and non-smokers) observed in baseline were $1.09 \pm 0.2 \%$ and further augmented with the cumulative dose as $1.47 \pm 0.3,2.4 \pm 0.5,3.47 \pm 0.5$, $5.3 \pm 1.02,7.52 \pm 1.3$ and $9.97 \pm 1.41 \%$ at $10,20,30,40,50$ and $60 \mathrm{~Gy}$ of the treatment. Therefore, all the patients exhibited significant $(\mathrm{p}<0.05, \mathrm{p}<0.01$ and $\mathrm{p}<0.001)$ increase of aberrations as indicated by the student's t-test at $95 \%$ confidence interval. Further, a significant (Rows: $\mathrm{p}<0.001 ; \mathrm{F}=17.56$ and column: $\mathrm{p}<0.001 ; \mathrm{F}=119.83$ ) interindividual variation of CAs between the patients and intra-individual variation within various doses of gamma radiation were also noted as per the two-way ANOVA.

While, the average qualitative CA frequency observed in pretherapy and post-therapy were noted within the patients as summarized in Table 2 . These various types of average CAs observed in baseline were breaks $(0.018 \pm 0.006)$, dicentrics $(0.011 \pm 0.003)$, rings $(0.004 \pm 0.002)$ and acentrics $(0.012 \pm 0.004)$. While, the CAs in post-treatment showed a more damage values in breaks $(0.170 \pm$ $0.030)$, dicentrics $(0.10 \pm 0.02)$, rings $(0.058 \pm 0.007)$ and acentrics $(0.070 \pm 0.013)$. The Student's $\mathrm{t}$-test showed a significant $(\mathrm{p}<0.05$, $\mathrm{p}<0.01$ ) variation between the average CAs frequency of pre-therapy and post-therapy values.

The average quantitative pre-therapy CAs in non-smoker were 0.93 $\pm 0.20 \%$ while smoker patients showed $1.26 \pm 0.10 \%$, which signifies the extra smoking effect before the treatment. Average CAs in nonsmokers after the $10 \mathrm{~Gy}$ dose of treatment showed damage of $1.35 \pm$ $0.40 \%$ and in smokers average CAs of $1.60 \pm 0.20 \%$ was noted. Further, the average values in non-smokers after completion of $20 \mathrm{~Gy}$ showed a CAs of $2.20 \pm 0.40 \%$ and smokers showed $2.60 \pm 0.50 \%$ which showed an augmented percentage of CAs with cumulative dose effects. The total CAs after the 30 Gy dose was $3.15 \pm 0.50 \%$ in non-smokers and higher value of $3.80 \pm 0.30 \%$ CAs in smokers was observed. The clastogenic effects after the $40 \mathrm{~Gy}$ of irradiation showed minimum damage of $4.65 \pm 0.60 \%$ in non-smokers while CAs of $5.95 \pm 0.90 \%$ was observed in smoker patients. Aberrations after the $50 \mathrm{~Gy}$ dose is $6.50 \pm 1.00 \%$ in non-smokers and damage of $8.55 \pm 0.90 \%$ in smokers was observed. The dose response in patients induced after $60 \mathrm{~Gy}$ showed a higher damage of $8.95 \pm 1.20 \%$ in non-smokers and aberrations of $11.00 \pm 0.60 \%$ were noted in smokers. 
Citation: Kadam SB, Shyama Sk, Kumar PMK, D'costa A, Almeida VG (2016) Cytogenetic Analysis on the Yields of Chromosomal Aberrations Induced by the Scattered Doses of Y-Radiation. J Nucl Med Radiat Ther 7: 270. doi:10.4172/2155-9619.1000270

Page 3 of 8

\begin{tabular}{|c|c|c|c|c|c|c|c|c|c|}
\hline \multirow{4}{*}{$\begin{array}{l}\text { Patient } \\
\text { no. }\end{array}$} & \multirow{4}{*}{$\begin{array}{l}\text { Sex/age } \\
(Y)\end{array}$} & \multirow{4}{*}{$\begin{array}{l}\text { Habits Smoker (S)/Non- } \\
\text { smoker (NS) }\end{array}$} & \multicolumn{7}{|c|}{ Percentage of chromosomal aberrations } \\
\hline & & & Control & \multicolumn{6}{|c|}{ Duration of treatment (dose in Gy) } \\
\hline & & & $\begin{array}{l}\text { Prior } \\
\text { treatment }\end{array}$ & I Week & II Week & III Week & IV Week & v Week & VI Week \\
\hline & & & (0 Gy) & (10 Gy) & (20 Gy) & (30 Gy) & (40 Gy) & (50 Gy) & (60 Gy) \\
\hline $\mathrm{P}_{1}$ & $\mathrm{~F} / 45$ & NS & $0.75 \pm 0.5$ & $1.0 \pm 0.5^{*}$ & $1.5 \pm 1.0^{\star}$ & $2.5 \pm 1.7^{\star \star}$ & $4.0 \pm 2.1^{\star \star}$ & $5.5 \pm 2.3^{\star \star \star *}$ & $7.25 \pm 2.6^{* \star *}$ \\
\hline $\mathrm{P}_{2}$ & $\mathrm{M} / 46$ & NS & $1.0 \pm 0.3$ & $1.5 \pm 0.5^{*}$ & $2.0 \pm 0.8^{*}$ & $2.75 \pm 1.7^{\star \star}$ & $4.25 \pm 2.8^{* *}$ & $6.0 \pm 3.5^{* *}$ & $8.5 \pm 3.8^{* * *}$ \\
\hline $\mathrm{P}_{3}$ & $\mathrm{M} / 37$ & NS & $0.75 \pm 0.5$ & $1.25 \pm 0.5^{*}$ & $2.25 \pm 1.8^{*}$ & $3.25 \pm 1.8^{* *}$ & $4.5 \pm 1.7^{* * *}$ & $6.25 \pm 2.6^{\star * *}$ & $9.0 \pm 4.2^{* \star *}$ \\
\hline $\mathrm{P}_{4}$ & $\mathrm{~F} / 56$ & NS & $0.9 \pm 0.2$ & $1.0 \pm 0.6^{*}$ & $2.5 \pm 1.2^{*}$ & $3.5 \pm 2.5^{* *}$ & $4.75 \pm 3.0^{* *}$ & $6.5 \pm 4.0^{* *}$ & $9.5 \pm 4.7^{* * *}$ \\
\hline$P_{5}$ & $M / 37$ & NS & $1.25 \pm 0.5$ & $1.75 \pm 0.9^{*}$ & $2.5 \pm 1.7^{*}$ & $3.5 \pm 2.6^{* *}$ & $4.75 \pm 3.0^{* *}$ & $7.75 \pm 4.7^{* *}$ & $10.0 \pm 5.5^{* * *}$ \\
\hline$P_{6}$ & $\mathrm{M} / 62$ & s & $1.0 \pm 0.2$ & $1.25 \pm 0.9^{*}$ & $2.25 \pm 1.2^{*}$ & $3.5 \pm 2.3^{* *}$ & $6.25 \pm 3.4^{* *}$ & $8.25 \pm 5.9^{* *}$ & $11.25 \pm 6.8^{* * *}$ \\
\hline $\mathrm{P}_{7}$ & $\mathrm{M} / 42$ & s & $1.25 \pm 0.6$ & $1.5 \pm 1.2^{*}$ & $3.0 \pm 1.4^{* *}$ & $4.25 \pm 3.2^{\star \star}$ & $7.25 \pm 3.4^{\star \star \star *}$ & $9.0 \pm 5.0^{* * *}$ & $10.75 \pm 5.9^{* * *}$ \\
\hline $\mathrm{P}_{8}$ & $\mathrm{M} / 69$ & s & $1.5 \pm 0.5$ & $1.75 \pm 0.9^{*}$ & $2.0 \pm 1.8^{*}$ & $3.75 \pm 2.3^{* *}$ & $5.5 \pm 3.0^{* *}$ & $9.0 \pm 4.3^{* * *}$ & $11.25 \pm 4.9^{* * *}$ \\
\hline $\mathrm{P}_{9}$ & $\mathrm{M} / 71$ & S & $1.25 \pm 0.5$ & $1.75 \pm 1.5^{*}$ & $3.25 \pm 1.8^{* *}$ & $4.0 \pm 2.7^{* *}$ & $6.0 \pm 4.9^{* *}$ & $8.75 \pm 6.3^{* *}$ & $11.75 \pm 6.8^{* * *}$ \\
\hline$P_{10}$ & $\mathrm{M} / 47$ & $s$ & $1.25 \pm 0.2$ & $2.0 \pm 1.4^{*}$ & $2.75 \pm 1.7^{*}$ & $3.75 \pm 1.7^{* *}$ & $5.75 \pm 2.5^{* * *}$ & $8.25 \pm 3.9^{* * *}$ & $10.5 \pm 5.8^{* * *}$ \\
\hline \multicolumn{3}{|c|}{ Average values of $N S\left(P_{1}\right.$ to $\left.P_{5}\right)$} & $0.93 \pm 0.20$ & $\begin{array}{ll}1.35 & \pm \\
0.40^{*} & \end{array}$ & $2.20 \pm 0.40^{*}$ & $3.15 \pm 0.50$ & $4.65 \pm 0.60$ & $6.50 \pm 1.00$ & $8.95 \pm 1.20$ \\
\hline \multicolumn{3}{|c|}{ Average values of $S\left(P_{6}\right.$ to $\left.P_{10}\right)$} & $1.26 \pm 0.10$ & $1.60 \pm 0.20$ & $2.60 \pm 0.50$ & $3.80 \pm 0.30^{* *}$ & $5.95 \pm 0.90^{* *}$ & $8.55 \pm 0.90^{* *}$ & $\begin{array}{l}11.00 \\
0.60^{* * *}\end{array}$ \\
\hline \multicolumn{3}{|c|}{ Average values of $N S+S\left(P_{1}\right.$ to $\left.P_{10}\right)$} & $1.09 \pm 0.20$ & $\begin{array}{l}1.47 \\
0.30^{*}\end{array}$ & $2.40 \pm 0.50^{*}$ & $3.47 \pm 0.50$ & $5.30 \pm 1.02^{* *}$ & $7.52 \pm 1.30^{* *}$ & $\begin{array}{l}09.97 \\
1.41^{* * \star *}\end{array}$ \\
\hline
\end{tabular}

Table 1: CAs in the study subjects. Data represents total CAs in peripheral blood lymphocytes of HNSCC patients before (0 Gy) and after various doses $(10,20,30,40,50$, and $60 \mathrm{~Gy})$ of RT as a mean \pm SD. Note: 1 . Student's t-test; shows statistically significant differences in total CAs at different doses compared with control values, ${ }^{*}$ represent $\mathrm{p}<0.05,{ }^{* *}$ represent $\mathrm{p}<0.01$ and ${ }^{* * *}$ represent $\mathrm{p}<0.001$. Note: 2 . Two way ANOVA; Interindividual variation showed significant (Rows: $\mathrm{p}<0.001 ; \mathrm{F}=17.56$ and column: $\mathrm{p}<0.001 ; \mathrm{F}=119.83$ ) difference by two way ANOVA. The nullhypothesis $\left[\mathrm{H}_{\mathrm{o}}\right]$ that "there are no inter and intra individual differences" was tested at 95\%, 99\%, 99.9\% confidence intervals. Abbreviations: $\mathrm{P}$ : Patient; S: Smoker; NS: Non-Smoker; M: Male; F: Female; RT: Radiotherapy; Y: Year and Gy: Gray.

\begin{tabular}{|c|c|c|c|c|c|c|c|c|c|c|c|c|}
\hline \multirow{3}{*}{$\begin{array}{l}\text { SI. } \\
\text { No }\end{array}$} & \multirow{3}{*}{$\begin{array}{l}\text { Sex/a } \\
\text { ge } \\
\text { (Y) }\end{array}$} & \multirow{3}{*}{$\begin{array}{l}\text { Habit: } \\
\text { Smoker (S)/Non- } \\
\text { smoker (NS) }\end{array}$} & \multicolumn{8}{|c|}{ Various CAs induced by gamma radiation and their frequency } & \multicolumn{2}{|c|}{$\begin{array}{l}\text { Frequency of total } \\
\text { CAs }\end{array}$} \\
\hline & & & \multicolumn{2}{|c|}{ Breaks } & \multicolumn{2}{|c|}{ Dicentrics } & \multicolumn{2}{|c|}{ Rings } & \multicolumn{2}{|c|}{ Acentrics } & \multirow[b]{2}{*}{0 Gy } & \multirow[b]{2}{*}{$60 \mathrm{~Gy}$} \\
\hline & & & $0 \mathrm{~Gy}$ & $60 \mathrm{~Gy}$ & $0 \mathrm{~Gy}$ & $60 \mathrm{~Gy}$ & 0 Gy & $60 \mathrm{~Gy}$ & 0 Gy & 60 Gy & & \\
\hline$P_{1}$ & $\mathrm{~F} / 45$ & NS & 0.01 & 0.11 & 0.01 & 0.07 & 0.01 & 0.06 & 0.01 & 0.05 & 0.01 & 0.29 \\
\hline $\mathrm{P}_{2}$ & $\mathrm{M} / 46$ & NS & 0.02 & 0.14 & 0.01 & 0.08 & 0 & 0.05 & 0.01 & 0.07 & 0.04 & 0.34 \\
\hline $\mathrm{P}_{3}$ & M/37 & NS & 0.01 & 0.15 & 0.01 & 0.09 & 0 & 0.06 & 0.01 & 0.06 & 0.03 & 0.36 \\
\hline $\mathrm{P}_{4}$ & $\mathrm{~F} / 56$ & NS & 0.01 & 0.16 & 0.01 & 0.1 & 0 & 0.05 & 0.02 & 0.07 & 0.04 & 0.38 \\
\hline$P_{5}$ & $\mathrm{M} / 37$ & NS & 0.02 & 0.17 & 0.01 & 0.12 & 0.01 & 0.05 & 0.01 & 0.06 & 0.05 & 0.4 \\
\hline $\mathrm{P}_{6}$ & M/62 & $S$ & 0.02 & 0.21 & 0.01 & 0.11 & 0 & 0.07 & 0.01 & 0.06 & 0.04 & 0.45 \\
\hline $\mathrm{P}_{7}$ & $\mathrm{M} / 42$ & $S$ & 0.02 & 0.19 & 0.02 & 0.1 & 0 & 0.05 & 0.01 & 0.09 & 0.05 & 0.43 \\
\hline$P_{8}$ & M/69 & $S$ & 0.02 & 0.18 & 0.01 & 0.12 & 0.01 & 0.07 & 0.02 & 0.08 & 0.06 & 0.45 \\
\hline$P_{9}$ & $\mathrm{M} / 71$ & $S$ & 0.02 & 0.21 & 0.01 & 0.13 & 0.01 & 0.06 & 0.01 & 0.07 & 0.05 & 0.47 \\
\hline
\end{tabular}


Citation: Kadam SB, Shyama Sk, Kumar PMK, D'costa A, Almeida VG (2016) Cytogenetic Analysis on the Yields of Chromosomal Aberrations Induced by the Scattered Doses of Y-Radiation. J Nucl Med Radiat Ther 7: 270. doi:10.4172/2155-9619.1000270

Page 4 of 8

\begin{tabular}{|c|c|c|c|c|c|c|c|c|c|c|c|c|c|c|c|c|c|c|}
\hline$P_{10}$ & $\mathrm{M} / 47$ & S & 0.03 & & 0.19 & & 0.01 & 0.08 & & 0 & & 0.06 & 0.01 & & 0.09 & 0.05 & & 0.42 \\
\hline \multicolumn{3}{|c|}{ Average values of $N S\left(P_{1}\right.$ to $\left.P_{5}\right)$} & $\begin{array}{l}0.014 \\
0.005\end{array}$ & & $\begin{array}{l}0.146 \\
0.020^{*}\end{array}$ & & $\begin{array}{l}0.010 \quad \pm \\
0.000\end{array}$ & $\begin{array}{l}0.092 \\
0.010^{*}\end{array}$ & & $\begin{array}{l}0.004 \\
0.002\end{array}$ & \pm & $\begin{array}{l}0.05 \\
0.005^{* *}\end{array}$ & $\begin{array}{l}0.010 \\
0.004\end{array}$ & \pm & $\begin{array}{ll}0.06 & \pm \\
0.008^{* *}\end{array}$ & $\begin{array}{l}0.030 \\
0.010\end{array}$ & & $\begin{array}{l}0.350 \pm \\
0.040^{* *}\end{array}$ \\
\hline \multicolumn{3}{|c|}{ Average values of $S\left(P_{6}\right.$ to $\left.P_{10}\right)$} & $\begin{array}{l}0.020 \\
0.004\end{array}$ & \pm & $\begin{array}{l}0.196 \\
0.010^{\star}\end{array}$ & \pm & $\begin{array}{l}0.012 \pm \\
0.004\end{array}$ & $\begin{array}{l}0.108 \\
0.010^{*}\end{array}$ & \pm & $\begin{array}{l}0.004 \\
0.002\end{array}$ & \pm & $\begin{array}{l}0.062 \pm \\
0.008^{*}\end{array}$ & $\begin{array}{l}0.012 \\
0.004\end{array}$ & \pm & $\begin{array}{l}0.07 \\
0.010^{\star *}\end{array}$ & $\begin{array}{l}0.050 \\
0.007\end{array}$ & \pm & $\begin{array}{l}0.44 \\
0.010^{* *}\end{array}$ \\
\hline \multicolumn{3}{|c|}{ Average of $N S+S\left(P_{1}\right.$ to $\left.P_{10}\right)$} & $\begin{array}{l}0.018 \\
0.006\end{array}$ & \pm & $\begin{array}{l}0.170 \\
0.030^{\star}\end{array}$ & & $\begin{array}{l}0.011 \quad \pm \\
0.003\end{array}$ & $\begin{array}{l}0.100 \\
0.020^{*}\end{array}$ & & $\begin{array}{l}0.004 \\
0.002\end{array}$ & \pm & $\begin{array}{l}0.058 \\
0.007^{*}\end{array} \quad \pm$ & $\begin{array}{l}0.012 \\
0.004\end{array}$ & \pm & $\begin{array}{l}0.07 \\
0.013^{* *}\end{array}$ & $\begin{array}{l}0.042 \\
0.014\end{array}$ & \pm & $\begin{array}{l}0.390 \\
0.050^{* *}\end{array}$ \\
\hline
\end{tabular}

Table 2: CA induced by gamma radiation in non-target tissues at the end of cumulative 60 Gy of radiotherapy in HNSCC patients. Note: Student's $\mathrm{t}$-test; shows statistically significant differences in total CAs at different doses compared with control values, ${ }^{*}$ represent $\mathrm{p}<0.05,{ }^{* *}$ represent $\mathrm{p}<0.01$. Abbreviations: P: Patient; S: Smoker; NS: Non-Smoker: M: Male; F: Female: RT: Radiotherapy; Y: Year and Gy: Gray.
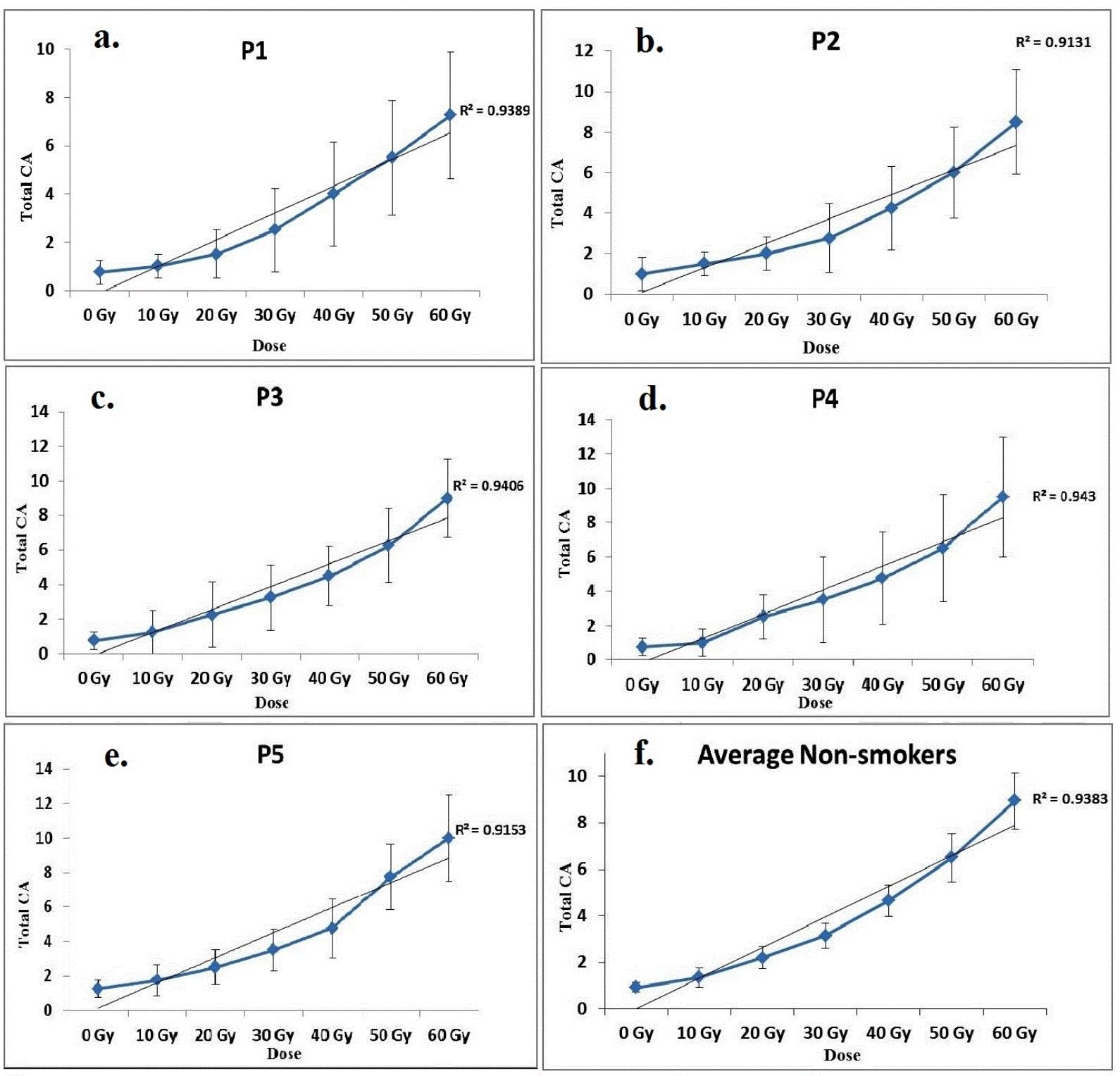

Figure 1: CAs exhibited in five non-smoker HNSCC patients $\left(\mathrm{P}_{1}-\mathrm{P}_{5}\right)$ at 0 Gy to various doses of RT (Graph a. to e.) and their average values (Graph $\mathrm{f}$ ) along with the values of their linear regression analysis. 
Citation: Kadam SB, Shyama Sk, Kumar PMK, D'costa A, Almeida VG (2016) Cytogenetic Analysis on the Yields of Chromosomal Aberrations Induced by the Scattered Doses of $Y$-Radiation . J Nucl Med Radiat Ther 7: 270. doi:10.4172/2155-9619.1000270

Page 5 of 8

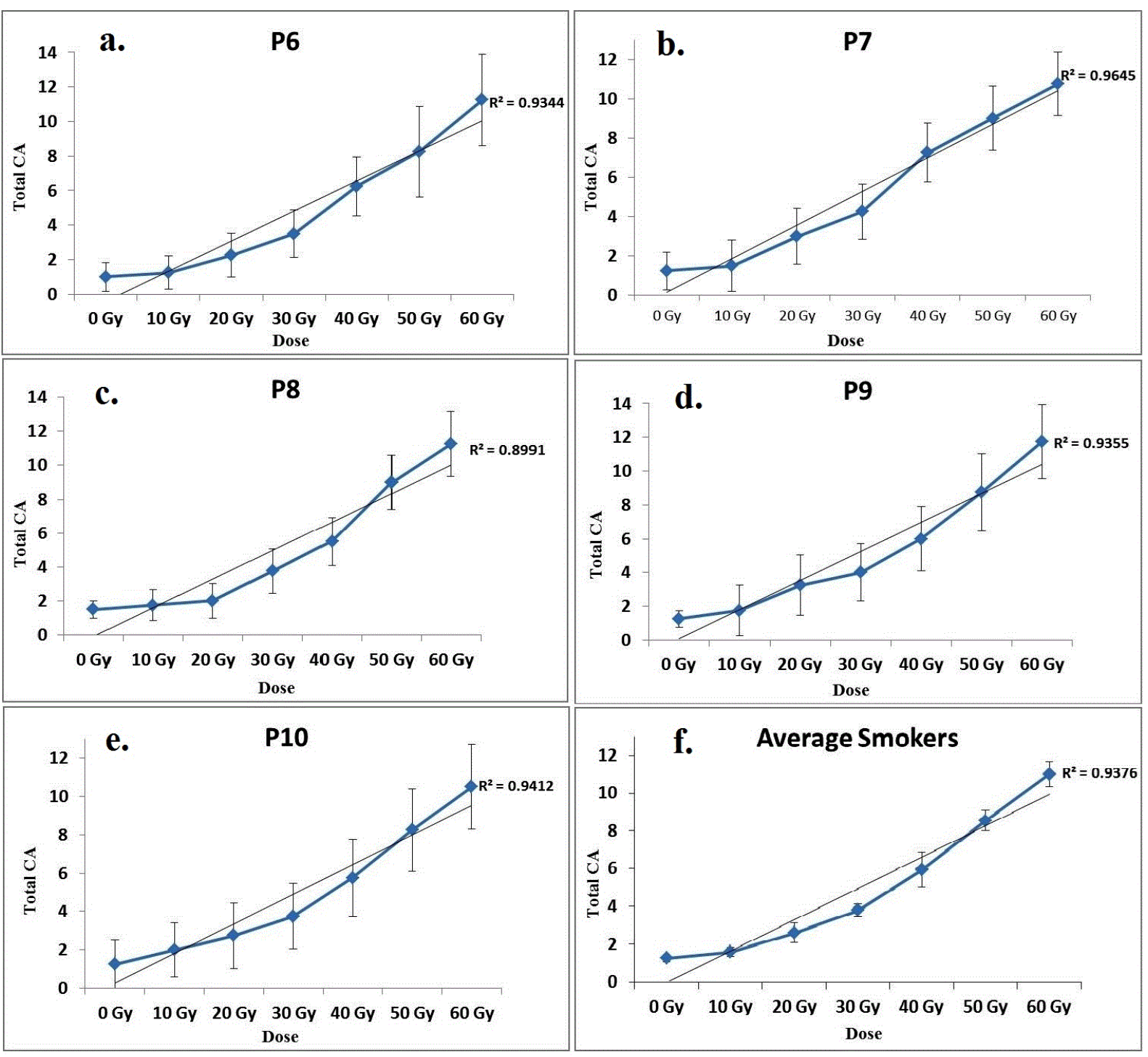

Figure 2: CAs exhibited in five smoker HNSCC patients $\left(\mathrm{P}_{6}-\mathrm{P}_{10}\right)$ at 0 Gy to various doses of RT and their average values are represented in the graphs a to e and average smokers graph in $\mathrm{f}$, along with the values of their linear regression analysis.

The results of qualitative CAs defined according to non-smoker and smokers were statistically significant $(\mathrm{p}<0.05, \mathrm{p}<0.01)$ when compared with the control values. Various kinds of CAs induced before treatment ( 0 Gy) and by the end of six weeks (60 Gy) of treatment with gamma radiation in individual smoker and non-smoker HNSCC patients and their frequency are shown in Table 1 . The average frequency of breaks observed in non-smokers before treatment was $0.014 \pm 0.005$ and $0.146 \pm 0.020$ after treatment were lower compared to smoker values i.e. $0.020 \pm 0.004$ and $0.196 \pm 0.010$. The dicentrics observed were $0.010 \pm 0.000$ in control values $(0 \mathrm{~Gy})$; while at the end of the treatment values seen were $0.092 \pm 0.010$ in non-smoker patients compared to smoker's average values observed was higher $0.012 \pm$ 0.004 and $0.108 \pm 0.010$. The rings were observed similar in nonsmokers and smokers before treatment $(0.004 \pm 0.002)$ and after treatment non-smokers $(0.054 \pm 0.005)$ compared to smoker's value i.e. $0.062 \pm 0.008$ was observed. Acentrics in non-smokers were $0.010 \pm$
0.004 found comparatively lower than smoker value $0.012 \pm 0.004$ in 0 Gy. While, the average values after end of the treatment were more in smokers $0.078 \pm 0.01$ then non-smoker value i.e. $0.062 \pm 0.008$. The total CAs in patients observed with higher frequency are 0.47 and lower frequency value of 0.29 . This denotes that there is variation in DNA damage in almost all patients.

Figure 3 shows a graphical representation between the smokers, non-smokers and total CAs (smokers + non-smokers) which demonstrates the difference between various types of CAs (breaks, dicentrics, rings and acentrics). The significance was noted at $\mathrm{p}<0.05$ and non-significant at $\mathrm{p}>0.05$ at $95 \%$ confidence interval between the smoker and non-smokers average values. The average total breaks in non-smokers were $15.0 \pm 2.9 \%$ and smokers showed $19.2 \pm 1.78 \%$ significant $(\mathrm{p}<0.01)$ variations in the values. While, average values of dicentrics was $8.4 \pm 1.14 \%$ (non-smokers) and $11.6 \pm 1.14 \%$ (smokers) showed significant variation $(\mathrm{p}<0.01)$. Further, the rings were not 
Citation: Kadam SB, Shyama Sk, Kumar PMK, D'costa A, Almeida VG (2016) Cytogenetic Analysis on the Yields of Chromosomal Aberrations Induced by the Scattered Doses of $\gamma$-Radiation . J Nucl Med Radiat Ther 7: 270. doi:10.4172/2155-9619.1000270

Page 6 of 8

significant $(p>0.05)$ when non-smoker and smoker patients were compared with each other as $5.6 \pm 0.54 \%, 6.0 \pm 1.0 \%$ and also the average values of acentrics as $6.8 \pm 1.48 \%$ and $7.2 \pm 1.3 \%$ were not significant $(\mathrm{p}>0.05)$.

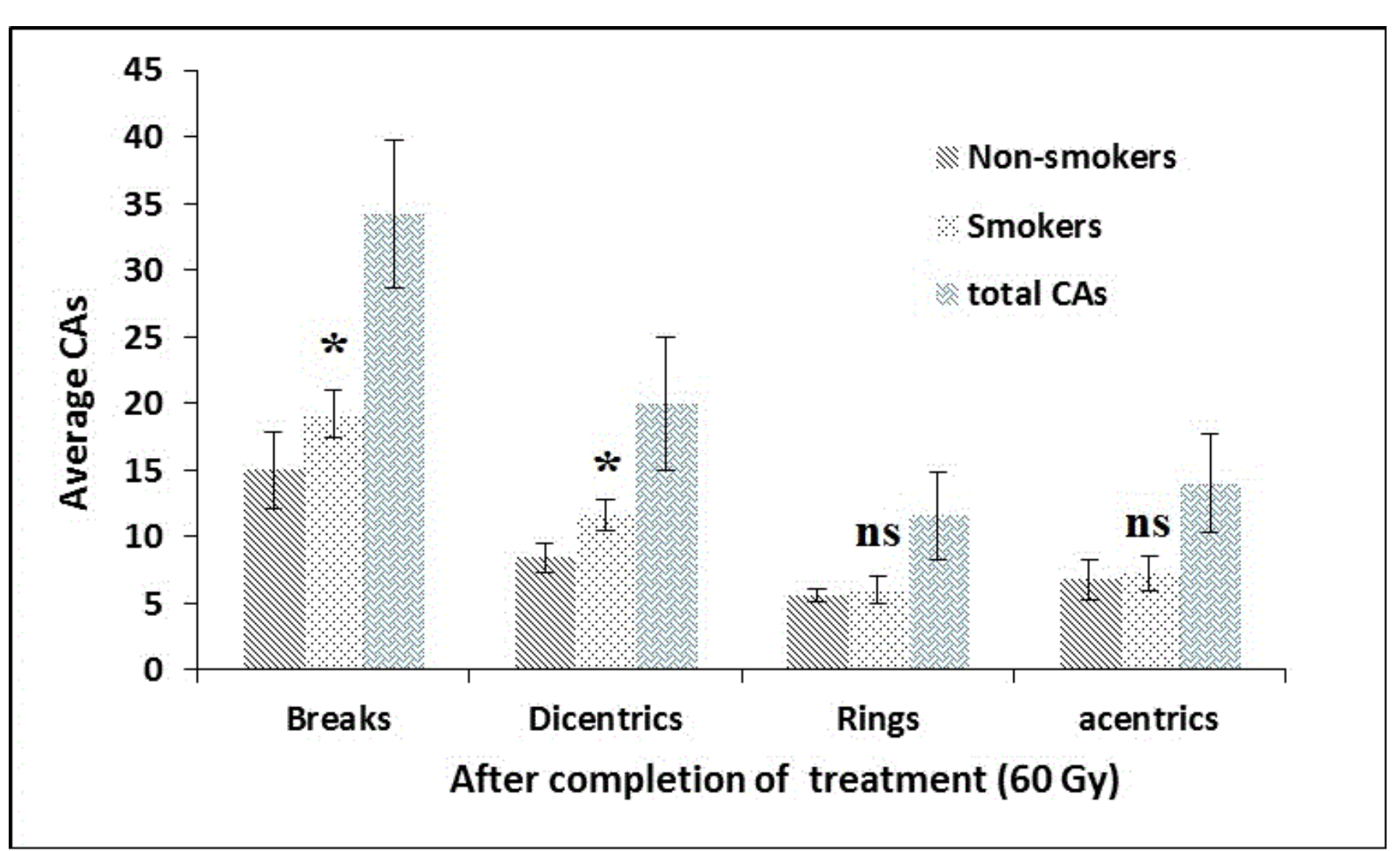

Figure 3: Comparison of CAs in non-smoker $\left(\mathrm{P}_{1}-\mathrm{P}_{5}\right)$ HNSCC patients with the smoker $\left(\mathrm{P}_{6}-\mathrm{P}_{10}\right)$ HNSCC patients using Student's t-test, after completion of treatment (i.e. $60 \mathrm{~Gy}$ ). Each point indicates the mean \pm SD of smokers and non-smokers. Note: ${ }^{*}$ represent statistically significant differences between smoker and non-smoker patients at $\mathrm{p}<0.05$; ns indicate a non-significant difference at $\mathrm{p}>0.05$.

\section{Discussion}

The present study was undertaken to quantify the amount of CAs induced by gamma rays in the non-target cells (peripheral blood lymphocytes) of HNSCC cancer patients $(n=10)$ irradiated with various doses at specific sites of head and neck region as a supplementary data for a better radiation dosimetry for tumour RT. CAs being a characteristic feature of radiation exposure is used as a potential biomarker of exposure [19]. Major kinds of structural chromosome anomalies induced by radiation in these patients were observed as shown in Table 2. Breaks, dicentrics rings and acentrics were observed as the chromosome aberrations following different radiation doses were recorded with acentric fragments associated with dicentrics and rings which were direct consequence of irradiation. We observed an elevated chromosome aberration significantly higher than the mean control value yield with a $95 \%$ confidence interval. Such a high yield may be explained for patients, whose head and neck cancer was treated with gamma radiation without the shields. However, the yield of various aberrations over the course of radiotherapy varied greatly in the HNSCC patients. Significant increase of CAs observed by us in the irradiated HNSCC patients recommends for a considerable reduction in the dose of gamma radiation for radiotherapy of HNSCC in comparison with the present dose of irradiation.
Natarajan reported CAs in the peripheral lymphocytes under circulation (non-cancerous cells) in various patients with solid tumour before RT [20]. Our present observations is in agreement with this report, where in we too could find a good number of CAs in cancer patients with solid tumours (HNSCC) prior to RT. However, Martin et al. could not find any CAs in the peripheral lymphocytes of patients with solid tumour which were analysed after fusion with golden hamster eggs [21]. Our previous findings also showed ex-vivo DNA damage in the leukocytes of head and neck cancer patients before and after RT [22].

Formation of CAs in peripheral lymphocytes by gamma rays during RT of cancer patients with solid tumours is reported by several scientists. According to Hayata peripheral lymphocytes do get exposed to radiation during RT and these results in various CAs in metaphase in the first cell division [23]. Our findings, that the CAs increase in the lymphocytes of HNSCC patients following RT, complements the above report. Further, Legal et al. also observed significant increase of CAs in breast cancer patients after external irradiation [24]. In addition to this, the increased CAs in the lymphocytes of cancer patient's was observed by Martin et al. following RT also supports our findings.

A dose dependent increase of CAs is reported in human lymphocytes in cancer patients undergoing RT. In fact, in most studies radiation has shown similar effects. Our outcomes also emphasised 
Citation: Kadam SB, Shyama Sk, Kumar PMK, D'costa A, Almeida VG (2016) Cytogenetic Analysis on the Yields of Chromosomal Aberrations Induced by the Scattered Doses of $Y$-Radiation . J Nucl Med Radiat Ther 7: 270. doi:10.4172/2155-9619.1000270

Page 7 of 8

that increasing the dose rate $(10,20,30,40,50,60 \mathrm{~Gy})$ lead to an increase in the proportion of circulating lymphocytes with DNA damage. Exposure to gamma radiation during RT increased the frequency of CAs and this condition is a significant risk for health. These damages may form secondary diseases such as leukaemia and anaemia $[25,26]$. Therefore, effects of RT applications on healthy cells must be minimized or alternative methods should be developed.

The pre-therapy/baseline DNA damage in peripheral lymphocytes of patients showed various levels of damages in different individuals, indicating inter-individual variations. These inter-individual variations may be mainly related to their lifestyle factors (including smoking habits) as well as various other inherited factors. Further, the large differences in the pre-treatment (0 Gy) levels of DNA damage between the smokers and non-smokers suggested that these variations may be due to the patient's lifestyle and/or genetic sensitivity. Genotoxicity in a cell is primarily dependent on the dose of the mutagen and/or its metabolites reaching the target area; however, the net damage is also dependent on the efficiency of DNA repair in the affected cells in the target area [27]. A thorough analysis of the baseline frequency of DNA damage is also important because this information has a direct bearing on the utility of these measurements for biological dosimetry, especially in cases where individuals are suspected to have been overexposed but no pre-exposed background DNA damage frequency is available.
Introduction of geno-toxicological methods in medical surveillance of cancer patients during RT could be important technique for the evaluation of radiation safety. This will be useful in the determination of optimum dose of gamma radiation for RT as well as in evaluating secondary cancer risk in case of HNSCC carcinoma which may have initial genome burden. This could be an important factor in biological dosimetry and also for individual therapy change.

\section{Conclusion}

Significant variation in DNA damage in different patients induced by irradiation as per Student's t-test may indicate a variation of radiation sensitivity. This may depend upon various anatomical features of these sites, including the density of lymph nodes and the extent of blood supply. A reduced size of tumor has to be observed weekly and accordingly reduction in penetration depth of dose has to be done. Because, the large field size of tumor at the beginning of treatment requires a high dose time and penetration depth of radiation and after 3rd week the size of tumor doesn't remain same it gets reduced but the penetration depth of dose remains the same which has more impact latter on the non-targeted cells as shown in Figure 4.

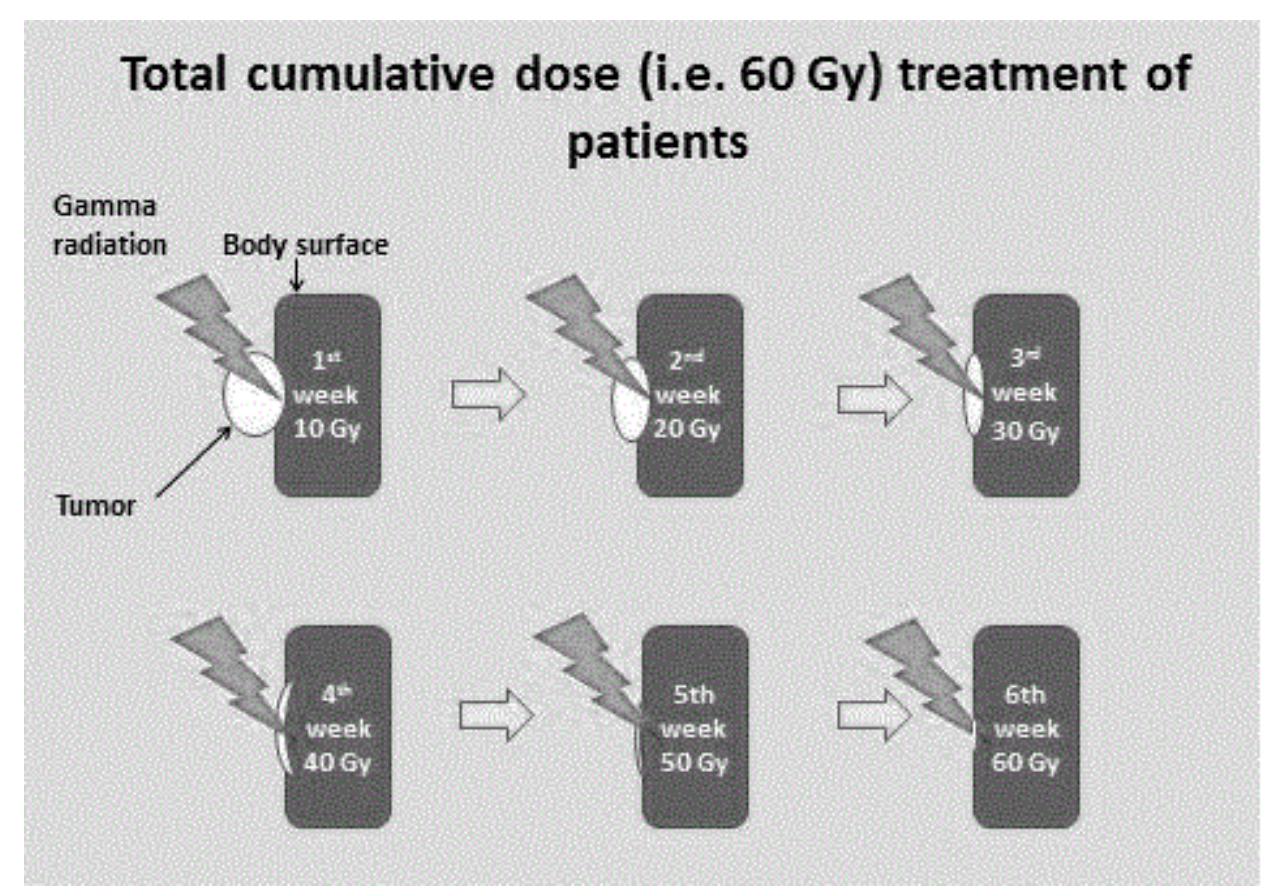

Figure 4: Figure 4 demonstrates a model where a reduced size of tumor has to be observed weekly and accordingly reduction in penetration depth of dose has to be done.

\section{Acknowledgement}

Author wishes to thank the University Grants Commission, New Delhi, India for providing a Meritorious Student Research Fellowship under the Basic Science Research Fund.

[Sanction No. F4-1/2006(BSR)/11-81/2008(BSR)]

\section{Conflict of Interest}

Authors do not have any conflicts of interest

\section{References}

1. Jemal A, Siegel R, Ward E, Hao Y, Xu J, et al. (2008) Cancer statistics, 2008. CA Cancer J Clin 58: 71-96. 
Citation: Kadam SB, Shyama Sk, Kumar PMK, D'costa A, Almeida VG (2016) Cytogenetic Analysis on the Yields of Chromosomal Aberrations Induced by the Scattered Doses of $Y$-Radiation . J Nucl Med Radiat Ther 7: 270. doi:10.4172/2155-9619.1000270

Page 8 of 8

2. Falk RT, Pickle LW, Brown LM, Mason TJ, Buffler PA, et al. (1989) Effect of smoking and alcohol consumption on laryngeal cancer risk in coastal Texas. Cancer Res 49: 4024-4029.

3. Merletti F, Boffetta P, Ciccone G, Mashberg A, Terracini B (1989) Role of tobacco and alcoholic beverages in the etiology of cancer of the oral cavity/oropharynx in Torino, Italy. Cancer Res 49: 4919-4924.

4. IARC Working Group on the Evaluation of Carcinogenic Risks to Humans (2004) Tobacco smoke and involuntary smoking. IARC Monogr Eval Carcinog Risks Hum 83: 1-1438.

5. Blasiak J, Arabski M, Krupa R, Wozniak K, Rykala J, et al. (2004) Basal, oxidative and alkylative DNA damage, DNA repair efficacy and mutagen sensitivity in breast cancer. Mutat Res 554: 139-148.

6. H Vaghef H, Nygren P, Edling C, Bergh J, Hellman B (1997) Alkaline single-cell gel electrophoresis and human biomonitoring for genotoxicity: a pilot study on breast cancer patients undergoing chemotherapy including cyclophosphamide. Mutat Res 395: 127-138.

7. Braybrooke JP, Houlbrook S, Crawley JE, Propper DJ, O'Byrne KJ, et al. (2000) Evaluation of the alkaline comet assay and urinary 3methyladenine excretion for monitoring DNA damage in melanoma patients treated with dacarbazine and tamoxifen. Cancer Chemother Pharmacol 45: 111-119.

8. N Kopjar N, Garaj-Vrhovac V, Milas I (2002) Assessment of chemotherapy-induced DNA damage in peripheral blood leukocytes of cancer patients using the alkaline comet assay. Teratog Carcinog Mutagen 22: 13-30.

9. Ramalho AT, Costa ML, Oliveira MS (1998) Conventional radiationbiological dosimetry using frequencies of unstable chromosome aberrations. Mutat Res 404: 97-100.

10. Bauchinger M (1995) Quantification of low-level radiation exposure by conventional chromosome aberration analysis. Mutat Res 339: 177-189.

11. IAEA (1986) Biological Dosimetry-Chromosomal Aberration Analysis for Dose Assessment. In: Technical Report Series, Editors IAEA, Vienna 260: 1-69.

12. Au WW, Cajas-Salazar N, Salama S (1998) Factors contributing to discrepancies in population monitoring studies. Mutat Res 400: 467-478.

13. Edwards AA (1997) The use of chromosomal aberrations in human lymphocytes for biological dosimetry. Radiat Res 148: S39-44.

14. IAEA (2001) Cytogenetic analysis for radiation dose assessment: a manual. Vienna: International Atomic Energy Agency.

15. Scarfi MR, Lioi MB, Zeni O, Franceschetti G, Franceschi C, et al. (1994) Lack of chromosomal aberration and micronucleus induction in human lymphocytes exposed to pulsed magnetic fields. Mutat Res 306: 129-133.
16. Siddique $\mathrm{YH}$, Ara G, Beg T, Afzal M (2007) Protective role of nordihydroguaiaretic acid (NDGA) against the genotoxic damage induced by ethynodiol diacetate in human lymphocytes in vitro. J Environ Biol 28: 279-282.

17. Savage JR (1976) Classification and relationships of induced chromosomal structual changes. J Med Genet 13: 103-122.

18. Anscombe FJ (1973) "Graphs in statistical analysis". The American Statistician 27: 17-21.

19. Ballarini F, Ottolenghi A (2003) Chromosome aberrations as biomarkers of radiation exposure: modelling basic mechanisms. Adv Space Res 31: 1557-1568.

20. Natarajan AT (2002) Chromosome aberrations: past, present and future. Mutat Res 504: 3-16.

21. Martin RH, Rademaker A, Hildebrand K, Barnes M, Arthur K, et al. (1989) A comparison of chromosomal aberrations induced by in vivo RT in human sperm and lymphocytes. Mutat Res 226: 21-30.

22. S Kadam SB, Shyama SK, Almeida VG (2013) Evaluation of the in vivo genotoxic effects of gamma radiation on the peripheral blood leukocytes of head and neck cancer patients undergoing radiotherapy. Mutat Res 752: $42-46$.

23. Hayata I (2000) Insignificant risk at low dose [rate] radiation predicted by cytogenetic studies. National Institute of Radiological Sciences, ChibaJapan: 263-8555.

24. Legal JD, De Crevoisier R, Lartigau E, Morsli K, Dossou J, et al. (2002) Chromosomal aberrations induced by chemotherapy and radiotherapy in lymphocytes from patients with breast carcinoma. Int J Radiat Oncol Biol Phys 52: 1186-1195.

25. F Maffei F, Angelini S, Forti GC, Lodi V, Violante FS, et al. (2002) Micronuclei frequencies in hospital workers occupationally exposed to low levels of ionizing radiation: Influence of smoking status and other factors. Mutagenesis 17: 405-409.

26. Muirhead CR, Goodill AA, Haylock RG, Vokes J, Little MP, et al. (1999) Occupational radiation exposure and mortality: Second analysis of the National Registry for Radiation Workers. J. Radiol. Protect. 19: 3-26.

27. Althouse R, Huff J, Tomatis L, Wilbourn J (1979) Chemicals and industrial processes associated with cancer in humans. IARC Monographs, Volumes 1 to 20. IARC Monogr Eval Carcinog Risk Chem Hum Suppl: 1-71. 